\title{
Improving aircraft cabin air quality by reducing Tri- Cresylic Phosphate
}

\section{Abstract}

Bleed air ECS extract air from engine compressor and is subject to increase the toxic chemicals in the cabin air. One of the most harmful of them is Tri-Cresylic Phosphate (TCP). It is a common anti-wear additive used in jet engine oils and exposure to this chemical increases the risks of various adverse health effects. Additionally, the European Aviation Safety Agency (EASA) which implements and monitors safety issues in aircrafts has yet to come up with an exposure limit for TCP's. The effect of TCP and its filtration is analyzed and showed that by means of Carbon Active filters can be reduced.
Volume 4 Issue 2 - 2020

\author{
A Zare Shahneh \\ Cranfield University, UK
}

Correspondence: A Zare Shahneh, Cranfield University, UK, Email a.shahneh@cranfield.ac.uk

Received: April 08, 2020 | Published: May 29, 2020

Keywords: TCP, bleed air, filters, fresh air supply, fume event, aero-toxic syndrome

\section{Introduction}

Current studies in cabin air quality have led to solutions to decrease the impact of air pollution in aircraft cabins. The air-cleaning system is partially capable to remove contaminants from the cabin air supply. As a result the contaminants within the cabin are of one of concerns in the Aerospace Industry. ${ }^{1}$ In recent years the cabin air has been the reason for several complaints made by aircraft frequent flyers primarily pilots and air crews having chronic health issues because of low-level exposure to toxic chemicals. The contaminants are currently of great concern and it needs to control volatile organic compounds, body odors, carbon dioxide and carbon monoxide to provide clean air is one of the functions of the Environmental Control System (ECS).
The air that is fed into the cabin is generally a combination of air that is bled-off the jet engines and re-circulated air. This purification is generally carried out by various air filters. The filters and the air purification technologies used by aircraft have considerable reduced contaminants from the cabin air. HEPA filter which is able to remove up to $99.97 \%$ of airborne particles with 0.3 micrometers in diameter is used. The pressure drops in this filter depends to the thickness but are generally marked as 300 Pascal. However, this type of filter is unable to filter out volatile organic compounds. Figure 1 illustrates the various components of an aircraft air-conditioning system where 1) flow control valve, 2) air cycle machine, 3) primary heat exchanger, 4) secondary heat exchanger, 5) re-heater, 6) condenser, 7) water collector, 8) ram air, 9) re-circulating filter, 10) re-circulating fan.

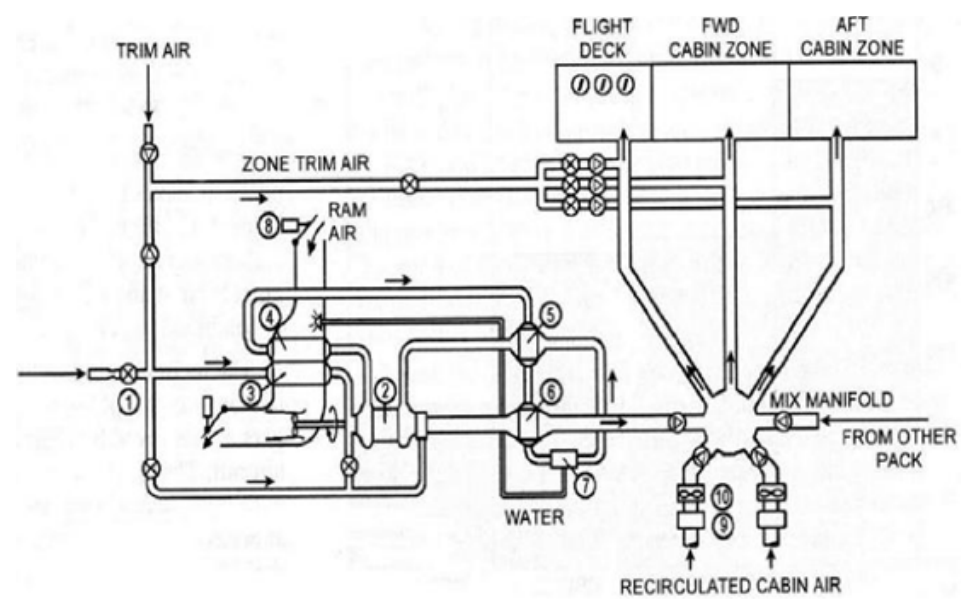

Figure I Typical aircraft air-conditioning system. ${ }^{2}$

TriCresyl Phosphate, a toxic source of contamination (TCP)

Pilot, cabin crew and passengers have reported their concerns regarding various chemical contaminants which have made them ill. The aviation workers have reported symptoms such as nausea, tunnel vision, fainting, memory loss, fatigue etc. ${ }^{3}$ Jet engine oil contains an organophosphate known as Tri-Cresylic Phosphate, a neurotoxin capable of damaging the central and peripheral nervous system where still is using in jet engine and lubricating oils for its load bearing and anti-wear properties. ${ }^{4,5}$ TCP is an organophosphate compound. It is basically an ester of cresol and phosphoric acid. It has three isomers as shown in Figure 2. It can have ten isomers of TCP using combination of different types. A couple of examples of TCP are shown in Figure 3 below. 
<smiles>Cc1ccccc1O</smiles><smiles>Cc1cccc(O)c1</smiles><smiles>Cc1ccc(O)cc1</smiles>

Figure 2 Chemical structure for ortho(left), meta(centre) and para(right) isomers.


Figure 3 Chemical structure of tri-o-cresylphosphate(left) and tri-p-cresyl phosphate(right).

This organophosphate compound is a renowned neurotoxin. It can cause acute toxic effects because of the presence of acetyl and butryl-cholinesterases. As TCP is an organophosphate it can cause effect such as delayed neuropathy which would not shoe until couple of weeks of the exposure. It can result in health effects such as abdominal pain, nausea, diarrhea and fatigue. Because of its severe

Table I Chronic symptoms because of exposure to contaminated bleed-air side effects and neurotoxicity TCP are not included on commercial products on purpose. Therefore, in this thesis ways to monitor and filter out TCP's from cabin air is studied. Despite its severe drawbacks it is heavily used in industrial applications such as flame retardants and fluid additives. TCP has been added to jet oils at 3\% over the last three decades because of its advantages. Although some of it can decompose during its use the ones that are left can get into the cabin air due to oil leakage in the engines. Recently there had been plenty of public reactions regarding this issue in which aircraft crew and passengers have been exposed to this TCP chemical as the bleed air system extracts air from the compressor stages of the aircraft.

\section{Aero-toxic syndrome}

Aero-toxic symptoms is a medical condition allegedly caused by exposure to contaminated bleed air resulted in either acute short term or chronic long term illnesses. ${ }^{6}$ The Table 1 shows a list of such health issues. However, the symptoms the different aircraft personnel suffered from varied from one person to another and as a result the medical doctors are still unable to consider this as scientifically proven. Toxic fumes that enter the cabin from the aircraft enginescompromises the health of aircraft crew and passengers contaminated air affects up to 200,000 people every year. Symptoms includes: balance issues, nausea, tremors, breathing problems, fatigue, memory loss, neurological illness, brain damage, severe headaches. ${ }^{\text {? }}$

\begin{tabular}{|c|c|c|c|c|}
\hline Respiratory & Neurological & Systemic & Psychiatric & Derma \\
\hline Cough & Headache & $\begin{array}{l}\text { Nausea, } \\
\text { vomiting }\end{array}$ & Anxiety & Rash \\
\hline Shortness of breath & $\begin{array}{l}\text { Slowed mental } \\
\text { processing }\end{array}$ & Fatigue & \multicolumn{2}{|c|}{ Sleep disturbance } \\
\hline Chest tightness & Difficult multi-asking & $\begin{array}{l}\text { Muscle } \\
\text { weakness }\end{array}$ & \multicolumn{2}{|l|}{ Depression } \\
\hline \multirow[t]{7}{*}{ Wheezing } & Memory impairment & palpitations & \multirow[t]{7}{*}{ PSD } & \\
\hline & $\begin{array}{l}\text { Concentration } \\
\text { difficult }\end{array}$ & Diarrhea & & \\
\hline & Visual changes & & & \\
\hline & Tremor & & & \\
\hline & Gait problems & & & \\
\hline & Paraesthesais & & & \\
\hline & Balance problems & & & \\
\hline
\end{tabular}

\section{Aircraft filters}

Aircraft currently use recirculation filters to remove particles in the air. Aircraft also use filter to reduce bio-effluent levels, volatile organic compounds and other toxic chemical substances that are present in aircraft cabin. In such case High efficiency particulate air (HEPA) filters are currently used to provide a healthy environment inside the cabin. HEPA filters were first invented in the early 1940's to stop the diffusion of airborne radioactive contaminants. ${ }^{8}$ HEPA filtration technology is used to control particle contaminants inside the aircraft cabin and provide a healthy breathing environment for the passengers and the crew. First in this chapter the mechanisms of this filter would be studied to see if it is sufficient to provide clean air inside the cabin. According to U.S environmental sciences and technology HEPA filters are designed to provide a very high right of efficiency of about $99.97 \%$ for particles as small as 0.3 microns in size. However, they are also capable of filtering out particles that are even smaller than 0.3 microns. ${ }^{9}$ On the other hand, the European Standard, EN 1822 Part 1 gives a range for the efficiency which is between $99.95 \%$ and $99.97 \%$. It provides details such the labelling, specification and performance testing for air filters. Besides HEPA filters it also details for Efficiency Particulate Air filters and Ultra Low Penetration Air Filters.

The performance of HEPA filter is described by pressure drop, permeability, lifetime resistance against environment and efficiency. Measurement of HEPA filter efficiency is mainly based on the size of the particles. HEPA filters provide an efficiency of at least $99.97 \%$ as shown in Figure 4. Figure 5 shows HEPA filter efficiency where Figure 6 shows the particle size range. 


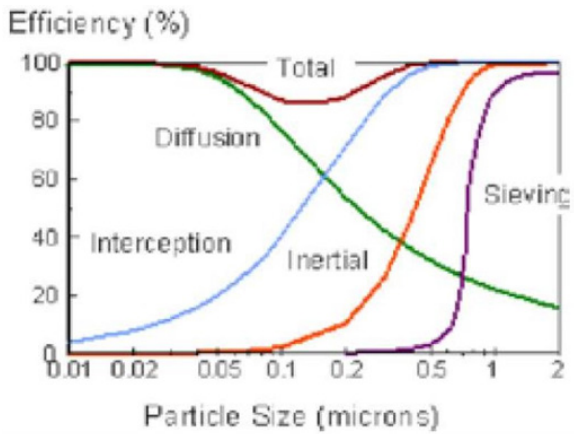

Figure 4 Filter efficiency in different methods against particle size (microns). ${ }^{10}$

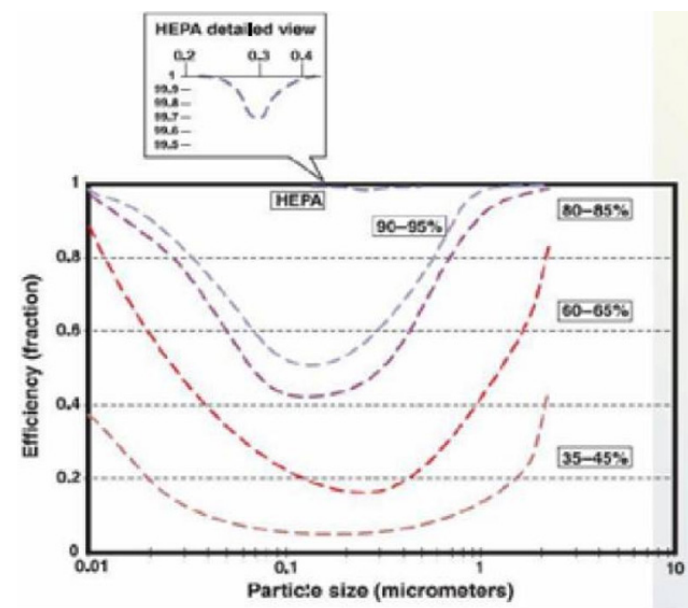

Figure 5 HEPA filter efficiency against particle size. ${ }^{10}$



Figure 6 Particle size chart. ${ }^{10}$

\section{Charcoal filter for removing TCP}

It can be summarized that although HEPA filters are excellent in removing airborne particles. However, they cannot remove volatile organic compounds such a TCP from the cabin air. Therefore, activated carbon absorbent charcoal filters have been chosen as the best option that should be used in aircrafts which uses bleed air technology. This type of activated carbon filters has high efficiency to absorb gaseous contaminants to a high temperature of about $80^{\circ} \mathrm{C}$ and it also does not consume electrical power from the aircraft. One disadvantage of such a system is that the filters need to replace periodically during maintenance as it gets ineffective with deposit of contaminants. This activated carbon filters can be placed in three places as discussed and shown in the Figure 6. First option would be to place the filters downstream of engines but the temperature here is quite high for activated charcoal filters that are currently available. Second option would be place them between the cooling packs and the mixed manifold. This is by far the best option as the temperature here is under control and suitable for carbon filters as well as all 'bleed air' would also be filtered in the process. Finally, the filter can also be placed after it has passed through the mixed manifold and can also be considered an option.

Activated carbon filter are currently developed by Pall Aerospace which are very light weight. They are very effective in absorbing volatile organic compounds which include TCP's. They have shown a removal efficiency of about $73 \%$ for TCP's in the gaseous phase. They have an initial removal efficiency of greater than $80 \%$ as declared by Toluene which states the standard of absorption in this field. The design specification and the airflow rates to design such activated carbon filters should be similar to the Boeing 737HEPA filters that are currently used. The specification of activated filter is shown in Table 2.

Table 2 Specification of HEPA carbon active filter (European source)

Sesign requirement

Figure 7 Various options to place the activated carbon filters.

\section{Conclusion and future work}

The quality of cabin air is one of the most important design criteria during aircraft design as it can have both short and long term adverse health effects for the crews and passengers. There are various sources 
for cabin air contamination which include de-icing fluids, exhaust fumes and paints amongst many others. However, the sources which seem to have the most detrimental health effects are the jet engine oils, lubricants and hydraulic fluids used in the engines. These sources emit various chemicals and of which TCP is one which has resulted in chronic health conditions particularly for aircraft crew members. At present, there it is still a worldwide debate going on whether actually TCP contaminants the cabin air. However, based on the reports published and the health effects such as nausea, skin irritation, fatigues it can be concluded that TCP is the prime factor as these symptoms are quite similar to the ones caused by TCP. The TCP which emits toxic fumes when heated to decomposition can cause severe neurological effects on the brain and the nervous system. However, till date it is still continued to be used because reasons such as:

a. It contains anti-wear additive which improves engine reliability

b. The air regulators still consider that at the measured levels it would be inconceivable that there would be any ill-effects on the aircraft crew as not everyone is affected.

To tackle this issue research work carried on contaminates in the aircraft cabin makes us aware that the cabin air is not safe as some agencies, organizations, medical doctors and manufacturers claims. Firstly an online monitoring method has been chosen to measure and detect TCP and secondly studies have been undertaken in terms of future filter technology. HEPA filter is the method that is currently used to filter airborne particles in the cabin. However, it only filters re-circulated air and is unable to filter organophosphates such as TCP. Hence, activated carbon absorbent filters have been chosen as a replacement to provide purified air inside the cabin.

Some of the recommendations to monitor and overcome this ongoing issue are listed below:

a. Using a bleed-less technology as it eliminated the whole concept of toxins entering the cabin air supply. This is currently only implemented by Boeing 787 Dreamliner which draws fresh air from the outside using nostril-type apertures at the wing roots on both sides of the fuselage. As a matter of fact, the auxiliary power unit of this aircraft is also free from bleed air. A recent air sampling trial on Boeing 787 Dreamliner found no results of TCP in the cabin air. b. Monitoring and detecting methods as studied by a group of researchers at Auburn University needs to be implemented in all aircrafts. It should also be developed as an automatic sensing system and placed in the air supply ducts so that it is able to detect TCP prior to entering the cabin.

\section{Acknowledgments}

None.

\section{Conflicts of interest}

Author declares that there is no conflict of interest.

\section{References}

1. Hunt DR, Space EH. The Airplane Cabin Environment: Issues Pertaining to Flight Attendant (1994); 1994.

2. ASHRAE Guidelines 28-2016. Air Quality within Commercial Aircraft. American Society of Heating, Refrigerating and Air-conditioning Engineers, Inc.: Atlanta, GA; 2016.

3. The Airliner Cabin Environment and the Health of Passengers and Crew. Washington D.C: National Academies Press; 2002.

4. Schopfer OLLM, Furlong CE. Development of Diagnostics in the Search for an Explanation of Aerotoxic Syndrome. Anal Biochem. 2010;404(1):64-74.

5. Ramsden JJ. Jet engine oil consumption as a surrogate for measuring chemical contamination in aircraft cabin air. $J$ Biol Phys Chem. 2013;13(4):114-118.

6. Aerotoxic Association; 2015.

7. Winder C, Balouet JC. Aerotoxic syndrome: adverse health effects following exposure to jet oil mist during commercial flights. Proceedings of the International Congress on Occupational Health Conference: Brisbane, Australuia; 2000. 36 p.

8. High-efficiency particulate air system (HEPA system) (air filtration system). Encyclopedia Britannica; 2013.

9. DOE-STD-3020-97: Specification for hepa filters used by doe contractors. D. of USA Energy: Washington D.C; 1997.

10. Bull K. Cabin air filtration: Helping to protect occupants from infectious diseases. Travel Med Infect Dis. 2008;6(3):142-144. 